\title{
TORTUGAS Y PLESIOSAURIOS DE LA FORMACIÓN LA COLONIA (CRETÁCICO SUPERIOR) DE PATAGONIA, ARGENTINA
}

\author{
Zulma GASPARINI y Marcelo de la FUENTE
}

Departamento Paleontología Vertebrados, Museo de La Plata, Paseo del Bosque, (1900)

La Plata, Argentina.

Gasparini, Z. y Fuente, M. de la. 2000. Tortugas y plesiosaurios de la Formación La Colonia (Cretácico Superior) de Patagonia, Argentina. [Turtles and plesiosaurs of the La Colonia Formation (Upper Cretaceous) from Patagonia, Argentina.] Revista Española de Paleontología, 15(1), 23-35. ISSN 0213-6937.

\begin{abstract}
The turtles and one plesiosaur of the La Colonia Formation (Upper Cretaceous) outcropping in the southern slopes of Macizo Nordpatagonico are described. The reptiles were found in La Colonia area, located in the central-north Chubut province. The chelonian fauna of La Colonia Formation is composed by at less five taxa of Chelidae (Pleurodira) and one of Meiolaniidae (Cryptodira). The new skull remains of Sulcusuchus erraini Gasparini and Spalletti, 1990 allow us to assign this species to a long-snout plesiosaur of the family Polycotylidae. From a paleobiogeographic point of view in La Colonia Formation reptil groups of different origin and geographic range were found together: South gondwanian chelonians and snakes, plesiosaurs related to North American species, and gondwanian theropods.
\end{abstract}

Keywords: Chelonii, Plesiosauria, La Colonia Formation, Upper Cretaceous, Patagonia, Argentina.

\section{RESUMEN}

Se describen las tortugas y un plesiosaurio de la Formación La Colonia (Cretácico Superior) que aflora en las laderas sur del Macizo Norpatagónico. Los reptiles proceden de un área conocida como La Colonia, situada en el centro-norte de la provincia del Chubut, Argentina. La queloniofauna de la Formación La Colonia está constituida por al menos cinco taxones de Chelidae (Pleurodira) y uno de Meiolaniidae (Cryptodira). Los nuevos restos craneanos recuperados de Sulcusuchus erraini Gasparini y Spalletti, 1990 permiten referir esta especie como un plesiosaurio longirrostro de la familia Polycotylidae. Desde un punto de vista paleobiogeográfico en la Formación La Colonia convergen grupos de reptiles de distinto origen y distribución geográfica: quelonios y serpientes surgondwánicos, plesiosaurios relacionados con especies norteamericanas y terópodos gondwánicos.

Palabras clave: Chelonii, Plesiosauria, Formación La Colonia, Cretácico Superior, Patagonia, Argentina.

\section{INTRODUCCIÓN}

En el marco del proyecto sobre vertebrados del Cretácico tardío del noreste de Patagonia, llevado a cabo por el Departamento Científico de Paleontología de Vertebrados del Museo de La Plata y el Museo E. Feruglio de Trelew (1996-1998), se efectuaron numerosos hallazgos de peces, reptiles, aves y mamíferos (Pascual et al., en prep). El área explorada se encuentra en las laderas del sur del Macizo Norpatagónico (Meseta de Somuncurá) en el norte-centro de la provincia de Chubut, en una zona conocida como La Colonia (Fig. 1; $\left.42^{\circ} 55^{\prime}-43^{\circ} 02^{\prime} \mathrm{S} ; 67^{\circ} 28^{\prime}-67^{\circ} 41^{\prime} \mathrm{O}\right)$. Los niveles portadores de vertebrados corresponden a la Fm. La Colonia (Pesce, 1979), unidad litoestratigráfica formada durante el Campaniense-Maastrichtiense (Pascual, com. pers.). González y Ardolino en un estudio aún inédito analizan detalladamente la litología de la Fm. La Colonia en el contexto estratigráfico regional, y hacen referencia a las distintas edades inferidas para esa formación. Estos autores reconocen en la Fm. La Colonia tres principales litofacies que representan ambientes de sedimentación continental, marino-marginal y marino. La mayoría de los vertebrados fueron hallados en el sector medio de la litofacies correspondiente al ambiente marino marginal (Pascual, com. pers.). 


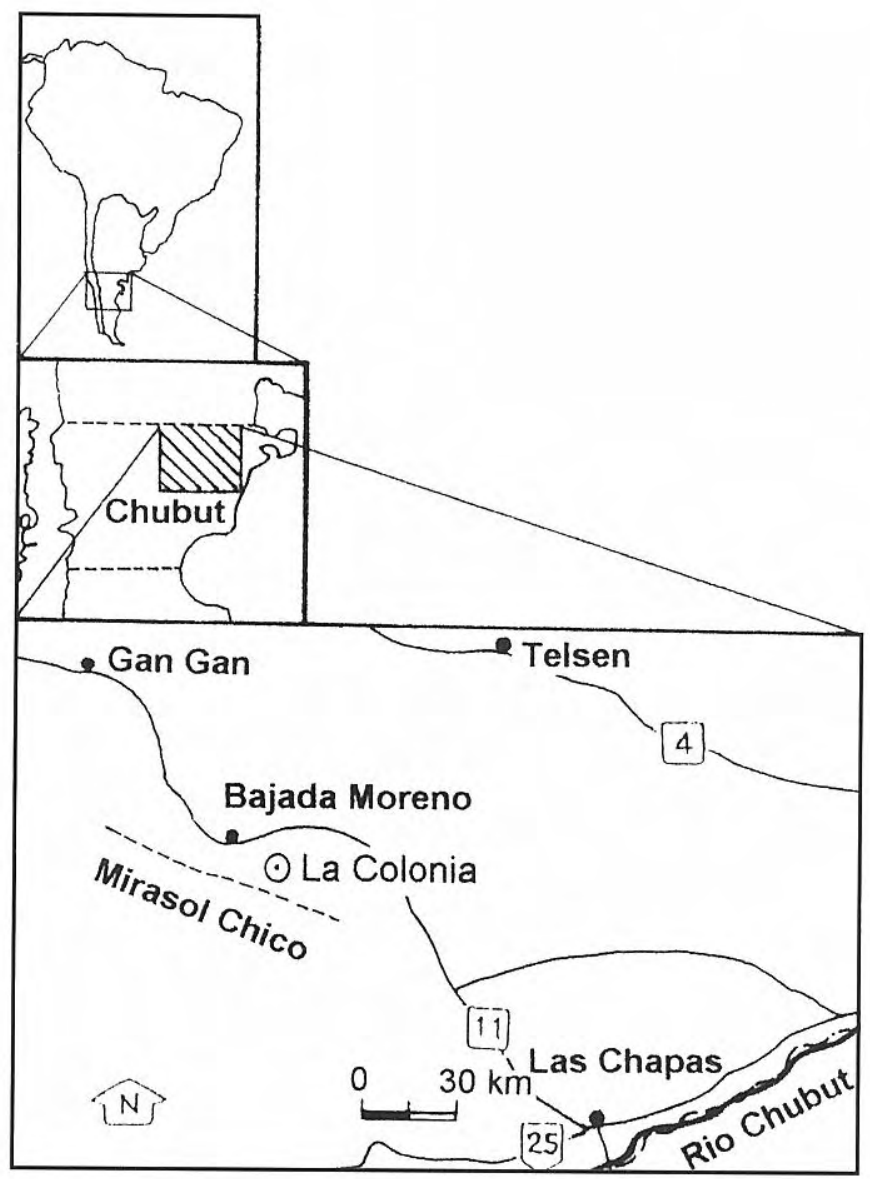

Figura 1. Mapa de ubicación del área de trabajo.

Hacia fines del Cretácico y hasta muy tempranamente en el Paleoceno, Patagonia fue ampliamente invadida desde el Atlántico Sur probablemente por más de una ingresión, transformando esa región en un amplio archipiélago (Legarreta et al., 1989) y separando, biogeográficamente, el sur de Patagonia del resto de América del Sur (Pascual et al., 1996). La Fm. La Colonia representa parte de los eventos de ascenso y descenso del nivel del mar, y en tal sentido es correlacionable con secuencias estratigráficas similares que se extienden en el centro y norte de Patagonia (Legarreta et al., 1989; Pascual et al., en prep.).

La mayor parte de los restos de vertebrados de la Fm. La Colonia son fragmentos pertenecientes a formas continentales. La herpetofauna está representada principalmente por quelonios y, en mucha menor proporción, por ofidios, dinosaurios y plesiosaurios. El material de tortugas está integrado por placas dérmicas y algunas vértebras cervicales y caudales asociadas, todas referibles a quélidos, además de un fragmento de la cornamenta de un meiolánido. Aunque entre los restos de plesiosaurios predominan los centros vertebrales aislados, se halló un esqueleto poscraneal (material aún sin preparar) y parte del cráneo de un plesiosaurio longirrostro. El estudio de este espécimen reviste especial interés porque demuestra que Sulcusuchus erraini Gasparini y Spalletti, 1990, originalmente determinado como un probable cocodrilo Dyrosauridae, es un plesiosaurio Polycotylidae. Desde el punto de vista paleobiogeográfico, en la fauna representada en la Fm. La Colonia convergen clados de reptiles de distinto origen y distribución geográfica, a la vez que de distintos ambientes. Mientras la queloniofauna de los niveles medios de la Fm. La Colonia está conformada por elementos surgondwánicos, equivalentes a los presentes en la Fm. Los Alamitos (Bonaparte et al., 1984) y otras unidades litoestratigráficas cretácicas de Patagonia (Broin, 1987; Broin y de la Fuente, 1993 a, b), los policotílidos longirrostros predominan en el "Western Interior Sea" de América del Norte (Bakker, 1993).

En este trabajo se describe el primer plesiosaurio longirrostro cretácico registrado en América del Sur, a la vez que se constata la presencia de nuevas especies, no nominadas, de quélidos y meiolánidos comprobándose una mayor diversidad en la queloniofauna gondwánica hacia fines del Mesozoico que la hasta ahora conocida. Todo el material que se describe en este trabajo pertenece al Museo Paleontológico Egidio Feruglio (MPEF) de Trelew, Chubut, Argentina.

\section{SISTEMÁTICA PALEONTOLÓGICA}

\section{ORDEN CHELONII Brongniart, 1800}

Las tortugas de la Formación La Colonia son en su mayoría Chelidae. Esta familia constituye un peculiar clado de pleurodiros surgondwánicos (ver Broin, 1987; Broin y de la Fuente, 1993 a, b) con un registro cretácico exclusivamente patagónico, que abarca el lapso temporal comprendido entre el Cretácico temprano (AlbienseCenomaniense) y el Cretácico tardío (Maastrichtiense) (Broin y de la Fuente, 1993 a, b; Lapparent de Broin et al., 1997; Lapparent de Broin y de la Fuente, 1999). En Patagonia, los quélidos son los componentes dominantes en las queloniofaunas continentales cretácicas y en la Formación La Colonia están representados por al menos cinco especies. Los criptodiros meiolánidos, componentes secundarios de estas faunas, presentes en menor número y diversidad, están probablemente representados por una especie en la Formación La Colonia. Aunque el material de quelonios recuperado de esta unidad litoestratigráfica es limitado y aún incompleto para nominar nuevos taxones, es posible reconocer distintas especies por la diversidad de tamaños, las diferentes morfologías y ornamentaciones de las placas óseas, así como por los diferentes rasgos de las vértebras cervicales.

\section{INFRAORDEN PLEURODIRA Cope, 1868 Familia Chelidae Gray, 1830}

Las tortugas Chelidae constituyen un grupo monofilético de pleurodiros (Gaffney, 1977; Gaffney y Meylan, 1988) cuyos registros se extienden desde el Cretácico Inferior hasta la actualidad en América del Sur (Broin y de la Fuente, 1993 a, b; Lapparent de Broin et 


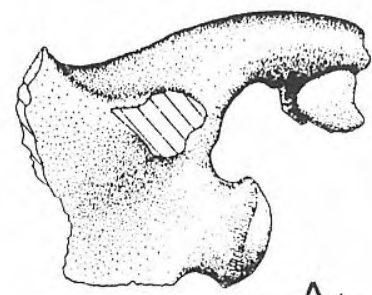

$A_{1}$

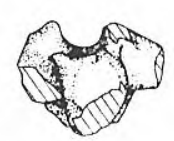

B1

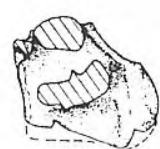

$\mathrm{B} 2$

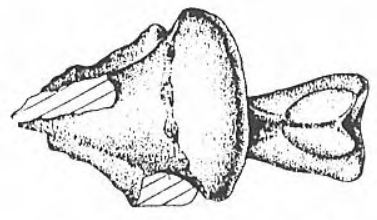

$\mathrm{A}_{2}$

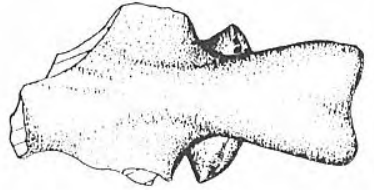

$\mathrm{A} 3$

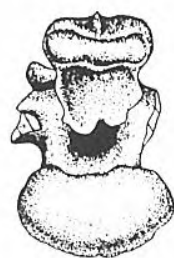

$\mathrm{A}_{4}$

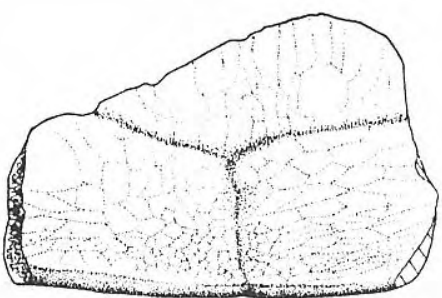

$\mathrm{D}_{1}$

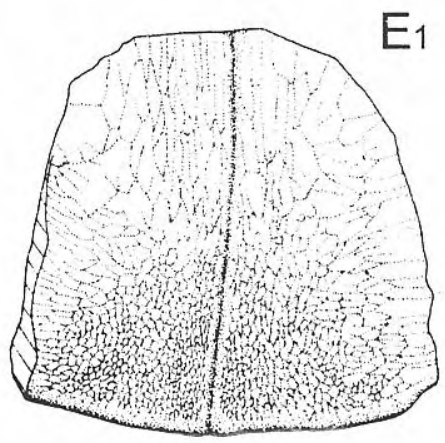

$E_{1}$
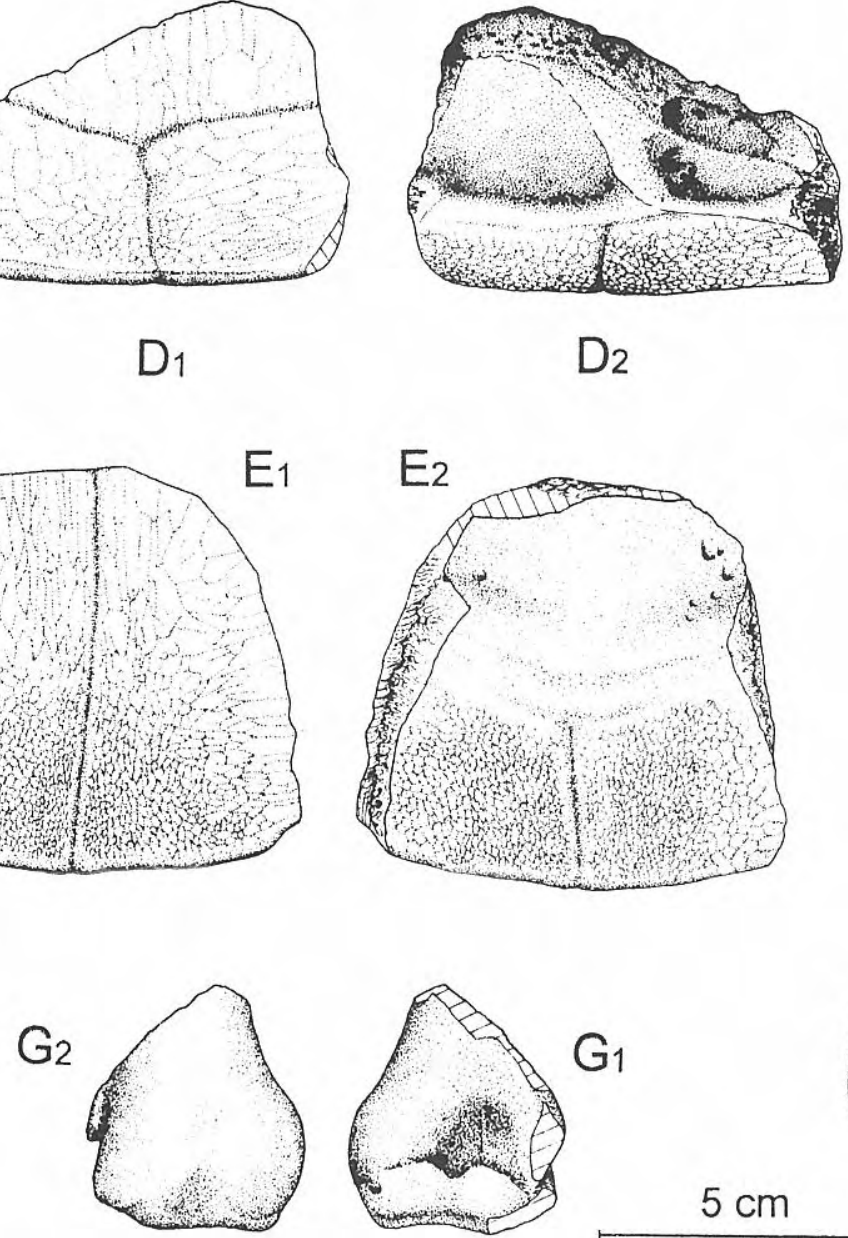

D2

$5 \mathrm{~cm}$

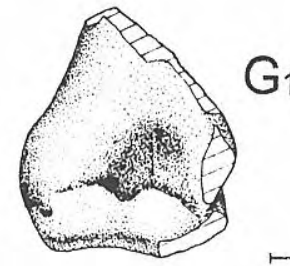

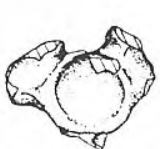

$\mathrm{B} 3$

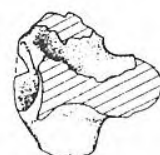

$\mathrm{B}_{4}$

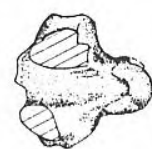

B5
$\mathrm{C}_{1}$

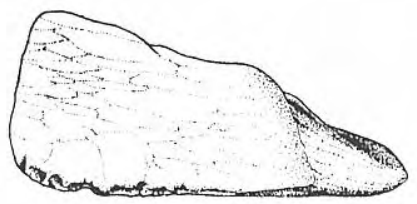

$\mathrm{C}_{2}$
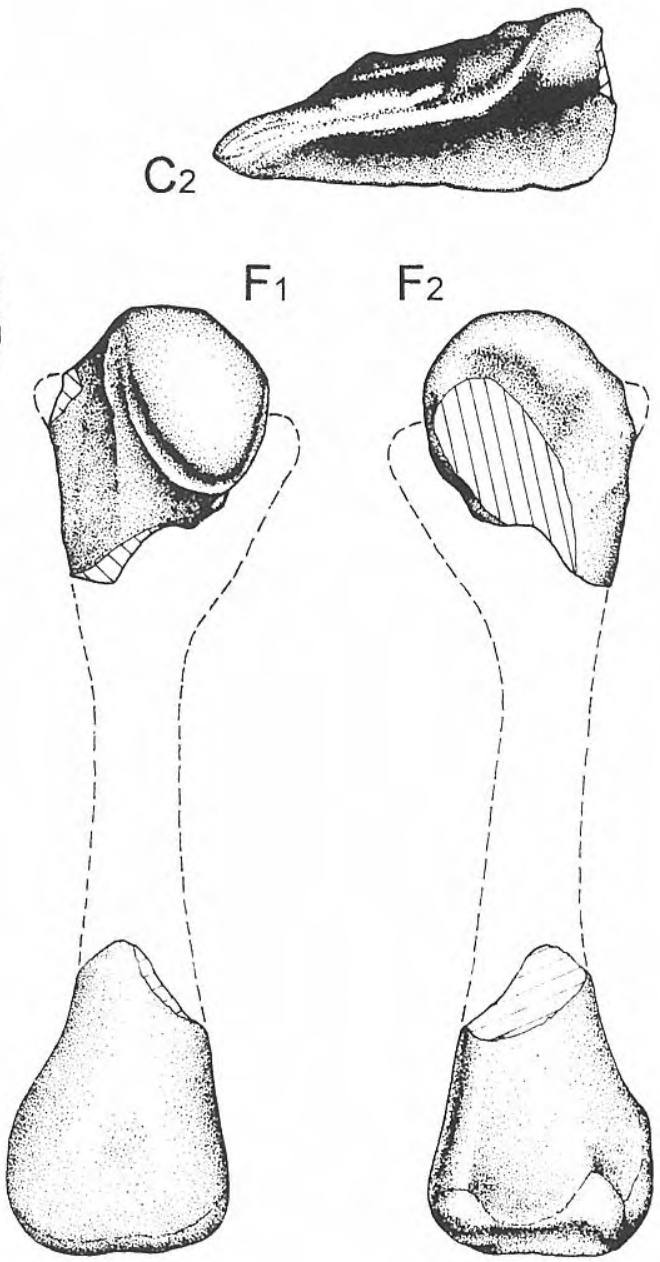

Figura 2. Cerro Bosta. Formación La Colonia (Cretácico Superior). Chelidae Gen. et sp. indet. 1. A. MPEF 933. Octava vértebra cervical: A1- vista lateral, A2- vista ventral, A3- vista dorsal, A4- vista posterior. B. MPEF 934. Vértebra caudal procélica: B1- vista posterior, B2- vista lateral, B3- vista anterior, B4- vista ventral, B5- vista dorsal. C. MPEF 890. Fragmento lateral de la primera placa pleural derecha: C1 - vista dorsal, C2- vista visceral. D. MPEF 845. Tercera placa periférica derecha: D1- vista dorsal, D2- vista visceral. E. MPEF 818. Placa pigal: E1-vista dorsal, E2- vista visceral. F. MPEF 954. Fragmento proximal y distal de un fémur derecho: F1- vista dorsal, F2vista ventral. G. MPEF 957. Fragmento distal de un húmero izquierdo: G1- vista dorsal, G2- vista ventral.

al., 1997) y desde el Eoceno hasta la actualidad en Australasia (Gaffney, 1981; Lapparent de Broin, com. pers.). El origen surgondwánico de esta familia explica su actual distribución disyunta en América del Sur, Australia y Nueva Guinea (Pritchard, 1984 a; Pritchard y Trebbau, 1984; Broin y de la Fuente, 1993 a, b). 
Entre el material de quélidos de la Fm. La Colonia predominan las placas óseas (117) en las que se distinguen fundamentalmente caracteres primitivos. Asociadas a algunas de estas placas dérmicas también se han recuperado 2 vértebras caudales, 3 vértebras cervicales (dos procélicas y una biconvexa) y restos del esqueleto apendicular. Los dos centros cervicales procélicos y el biconvexo presentan rasgos morfológicos que sugieren su ubicación como la sexta y octava vértebras en la serie cervical del cuello de tres diferentes individuos. Esta disposición es coincidente con el patrón de centros vertebrales cervicales que se reconoce en los quélidos vivientes: )1( (2( (3( (4( (5) )6) )7( (8). Asimismo, una de la vértebras estudiadas (MPEF 933) muestra rasgos derivados presentes en los grupos de quélidos más avanzados: la octava vértebra cervical biconvexa elongada. Estos rasgos derivados en la octava cervical están presentes en los quélidos actuales de cuello largo (Chelodina Fitzinger e Hydromedusa Wagler) en los cuales las vértebras cervicales son más largas que las dorsales suturadas al caparazón (ver Shaeffer et al., 1997).

\section{Procedencia geográfica y estratigráfica}

Cerro Bosta, ladera sur del Macizo Norpatagónico, centro-norte de la provincia de Chubut, Argentina (Fig. 1). Miembro medio de la Fm. La Colonia, niveles con Reigitherium Bonaparte, Campaniense tardío-Maastrichtiense (Pascual, com. pers.).

\section{Chelidae Gen. et sp. indet. 1}

Fig. 2, A-G

\section{Material}

MPEF 933: octava vértebra cervical biconvexa, MPEF 844 y 848: placas periféricas indet. del puente, MPEF 845: tercera placa periférica derecha, MPEF 818: placa pigal, MPEF 890: fragmento lateral de la primera pleural derecha, MPEF 891: séptima placa pleural derecha, MPEF 821: placa periférica indeterminada del borde posterior del caparazón, MPEF 934: vértebra caudal procélica, MPEF 957: extremo distal de húmero izquierdo, MPEF 954: fémur derecho.

\section{Observaciones}

El caparazón de este quélido indeterminado está representado por placas periféricas del puente, periféricas posteriores y placas pleurales correspondientes a diferentes individuos. Por las proporciones (longitud, anchura y espesor) de las placas aisladas, y su comparación con ejemplares más completos con similares rasgos morfológicos, recientemente recuperados en la Formación Salamanca del Paleoceno inferior de Patagonia (Bona et al., 1998), es posible estimar el largo lineal del caparazón dorsal en más de 60 $\mathrm{cm}$. El caparazón de los ejemplares arriba mencionados está caracterizado por presentar una decoración irregularmente distribuida sobre el mismo, consistente en los típicos polígonos irregulares presentes en los quélidos. Esta especie se corresponde con la especie ornamentada conocida por especímenes de gran dimensión lineal de Los Alamitos (ver Broin, 1987; Broin y de la Fuente, 1993 b). Asociada con una placa periférica del puente (MPEF 848) se recuperó una octava vértebra cervical (MPEF 933) posiblemente biconvexa. El centro vertebral de la misma es largo y bajo como el que se observa en los quélidos de cuello largo del grupo Hydromedusa. Sólo la mitad posterior del centro vertebral está preservado, no se conserva el centro articular anterior ni las prezigapófisis. A pesar de ello, y a partir de su comparación con las series de vértebras cervicales de especies actuales suramericanas referidas al género Hydromedusa Wagler [H. tectifera Cope e $H$. maximiliani (Mikan)] y algunas especies australasiáticas referidas a Chelodina Fitzinger ( $C$. oblonga Gray, $C$. expansa Gray) es posible identificar el resto conservado como una octava vértebra cervical biconvexa. En la superficie ventral se observan los restos de la cresta ventral que termina abruptamente y no alcanza el cóndilo articular posterior. El mismo es casi dos veces más ancho que alto y fuertemente convexo. El arco neural termina en un pedúnculo neural relativamente alargado que soporta sobre la superficie ventral las postzigapófisis. En vista posterior, entre el extremo caudal de las postzigapofisis y el extremo distal del pedúnculo, se distingue una concavidad bien definida. La misma no se observa en la octava vértebra de las especies actuales de Hydromedusa.

Una vértebra caudal procélica (MPEF 934) aislada podría corresponder a un espécimen de gran talla de la especie 1. En ese ejemplar (MPEF 934), el cóndilo central de esta vértebra caudal es de contorno redondeado, tan alto como ancho. El arco neural no está conservado. Sólo el proceso transverso izquierdo está presente. El cóndilo posterior es más alto que ancho. Su morfología general es consistente con la de los especímenes de Hydromedusa tectifera, salvando las diferencias de tamaño.

A la especie 1 se podrían también referir fragmentos aislados del esqueleto apendicular de especímenes de gran tamaño. Entre estos se puede reconocer el ejemplar MPEF 957 consistente en el extremo distal de un húmero izquierdo. Sobre la superficie dorsal de este hueso se distingue el extremo del surco ectepicondilar de posición muy lateral. La superficie articular está erosionada en gran parte, sobre todo el área ocupada por la tróclea. El capitellum, la pequeña superficie que articula con el radio, está mejor conservada en la vista ventral. Por encima de esta superficie articular se distingue un área deprimida.

El extremo distal y un fragmento proximal de un fémur derecho corresponden al ejemplar MPEF 954. El extremo distal está lateralmente expandido y la superficie articular erosionada en gran parte. De esta superficie, sólo la tibial está parcialmente conservada. La pequeña área fibular para la articulación de la fíbula, expuesta en vista ventral, está fuertemente desgastada. El extremo próximal conserva el trocánter mayor y una cabeza estrecha de contorno oval elongado. Otro extremo proximal de un 

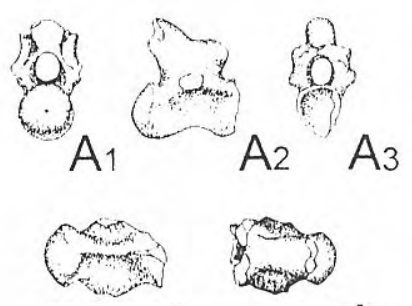

$A_{4}$

A5

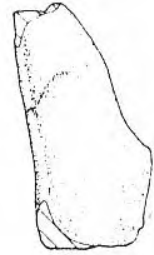

B1

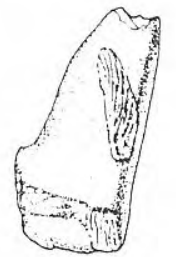

B2

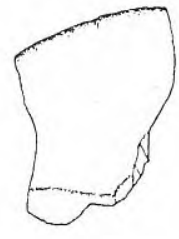

$\mathrm{C}_{1}$

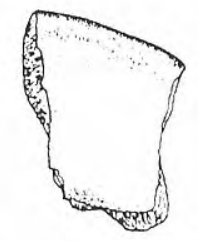

$\mathrm{C}_{2}$

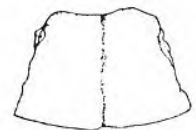

$D_{1}$

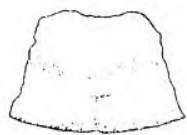

$D_{2}$

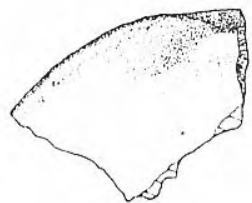

$E_{1}$

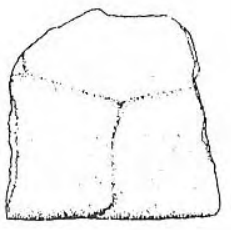

$\mathrm{H}$

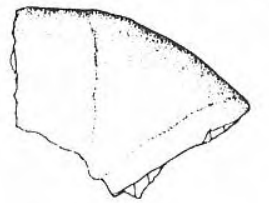

$E_{2}$

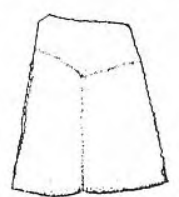

$F_{1}$

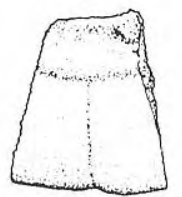

$\mathrm{F}_{2}$
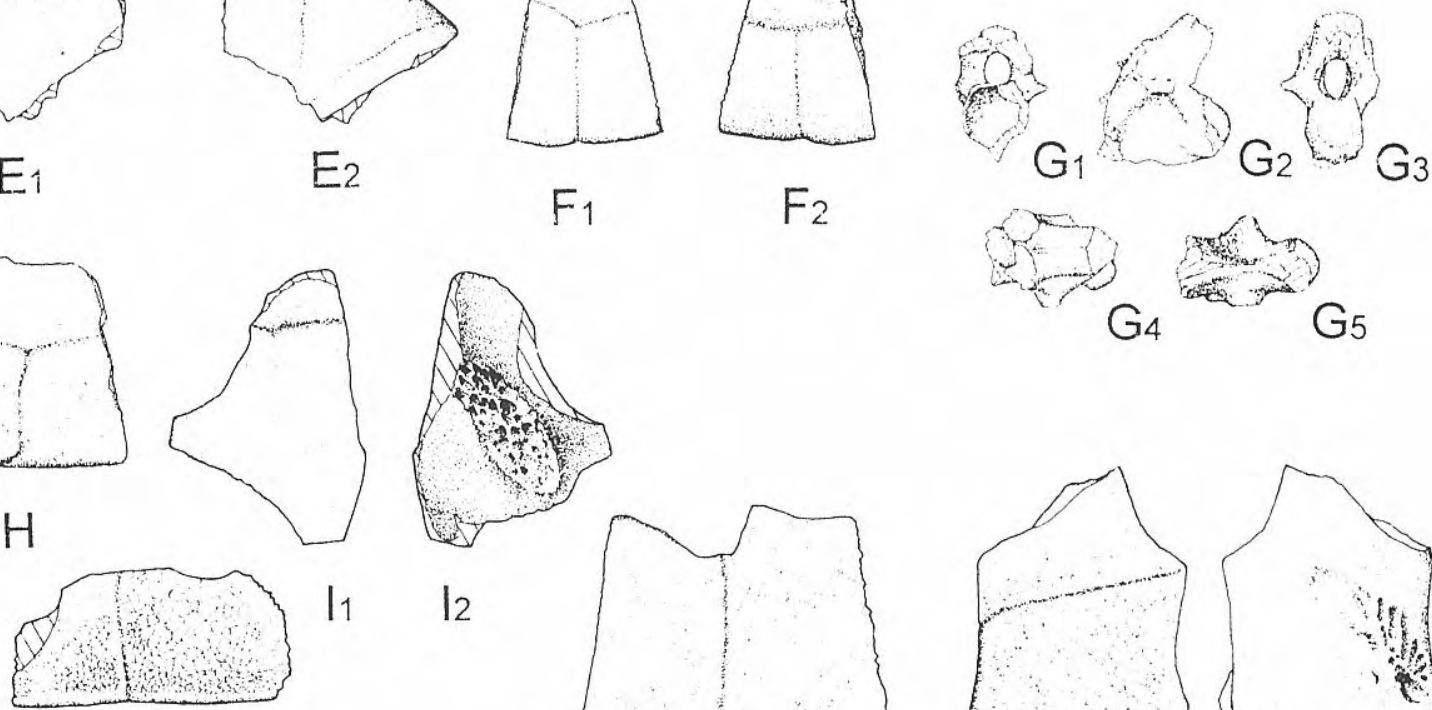

L

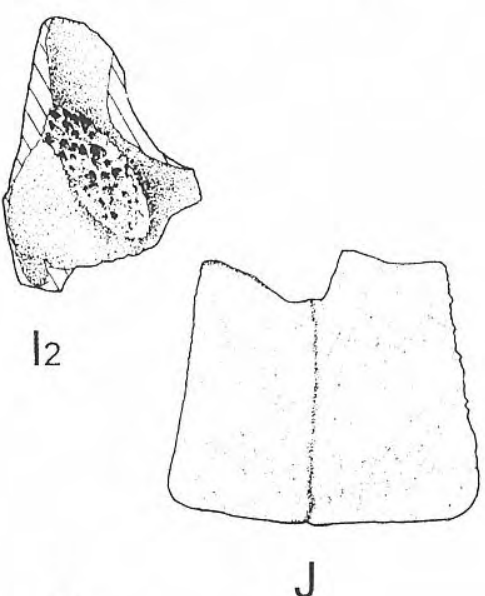

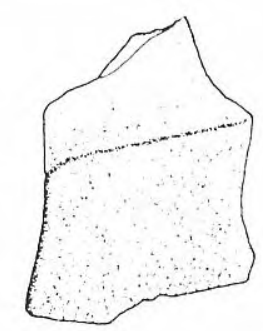

$\mathrm{K}_{1}$

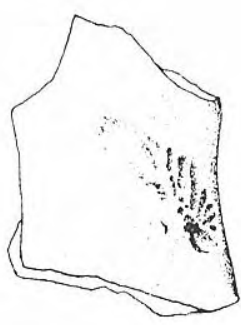

$\mathrm{K}_{2}$

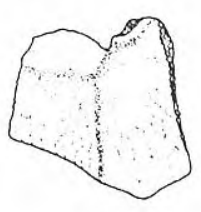

M

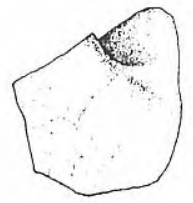

$\mathrm{N}_{2}$

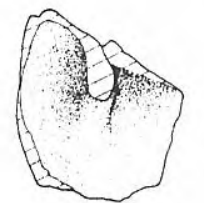

$\mathrm{N}_{1}$

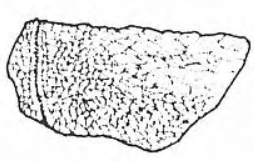

$\tilde{N}$

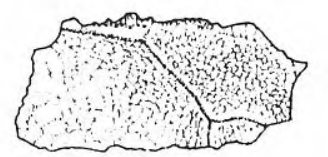

O

Figura 3. Cerro Bosta. Formación La Colonia (Cretácico Superior).

Chelidae Gen. et sp. indet. 2. (A-F). A. MPEF 932. Sexta vértebra cervical procélica: A1- vista posterior, A2- vista lateral, A3- vista anterior, A4- vista ventral, A5- vista dorsal. B. MPEF 908. Xifiplastron derecho: B1- vista dorsal, B2- vista visceral. C. MPEF 826. Primera placa periférica izquierda: C1- vista dorsal, C2- vista visceral. D. MPEF 820. Placa pigal: D1- vista dorsal, D2- vista visceral. E. MPEF 913. Fragmento del epiplastron izquierdo: E1- vista visceral, E2- vista ventral. F. MPEF 842. Undécima placa periférica izquierda: F1 - vista dorsal, F2- vista visceral.

Chelidae Gen. et sp. indet. 3. (G-I). G. MPEF 935. Sexta vértebra cervical procélica: G1- vista anterior, G2- vista lateral, G3- vista posterior, G4- vista dorsal, G5- vista ventral. H. MPEF 875. Placa periférica del puente, vista dorsal. I. MPEF 911. Fragmento del xifiplastron derecho: I1 - vista dorsal, I2- vista visceral.

Chelidae Gen. et sp. indet. 4 (J-L). J. MPEF 834. Placa periférica del borde posterior del caparazón, vista dorsal. K. MPEF 910. Fragmento xifiplastral: K1-vista ventral, K2- vista visceral. L. MPEF 878. Placa periférica del puente, vista lateral.

Chelidae Gen. et sp. indet. 5 (M-O). M. MPEF 839: Placa periférica posterior, vista dorsal. N. MPEF 865 fragmento de hioplastron izquierdo: N1- vista ventral, N2- vista visceral. Ñ. MPEF 895. Placa pleural indet., vista dorsal. O. MPEF 897. Placa pleural indet., vista dorsal.

fémur derecho conserva la cabeza estrecha, de contorno oval elongado, la base del trocánter mayor y el trocánter menor completo, los cuales limitan una estrecha fosa intertrocantérica. 
Chelidae Gen. et sp. indet. 2

Fig. 3, A-F

\section{Material}

MPEF 932: sexta vértebra cervical procélica, MPEF 913: epiplastron izquierdo, MPEF 820: placa pigal, MPEF 826: primera placa periférica izquierda, MPEF 842: undécima placa periférica del borde posterior izquierdo del caparazón, MPEF 908: xifiplastron derecho.

\section{Observaciones}

Este quélido aún indeterminado está representado por una sexta cervical procélica (MPEF 932). El centro vertebral es corto y alto (condición primitiva para quélidos). Los cóndilos articulares anterior y posterior son, respectivamente, ovalados y redondeados, ligeramente más altos que anchos. Una cresta ventral curvada recorre el largo del cuerpo vertebral. Los procesos transversos, mal conservados, se sitúan en la base del arco neural y en el medio del centro vertebral. Las prezigapófisis no se preservan. La base del pedúnculo que soporta las postzigapófisis (no preservadas) forma con el eje mayor del centro vertebral un ángulo de $40^{\circ}$. Un valor angular diferente se observa en las especies australianas de centro vertebral corto, tales como Elseya dentata (Gray) o Emydura macquarii (Gray). Esta vértebra presenta una morfología similar a la sexta vértebra cervical procélica ilustrada por Broin y de la Fuente (1993 b: Lám. 1; 1 a,b,c,d) de la localidad patagónica de El Abra (provincia de Río Negro), por lo que este mismo quélido (aún indeterminado por su naturaleza fragmentaria) con rasgos primitivos estaría presente en ambas localidades cretácicas de Patagonia. Sobre la base de las similares dimensiones y los rasgos primitivos presentes en la vértebra cervical (MPEF 913) y las placas dérmicas del caparazón (sin ornamentación), se propone como hipótesis la adjudicación a una misma especie de la vértebra cervical mencionada, las placas periféricas del margen anterior (MPEF 826) y el posterior (MPEF 842) del caparazón, la pigal (MPEF 820) y los fragmentos del epiplastron (MPEF 913). Estas placas indicarían la existencia de una especie no decorada de pequeñas dimensiones (caparazones dorsales estimados en 15 a $30 \mathrm{~cm}$ ). El hallazgo de nuevos ejemplares con vértebras cervicales asociadas permitirá confirmar o rechazar la hipótesis planteada.

\section{Chelidae Gen. et sp. indet. 3 Fig. 3, G-I}

\section{Material}

MPEF 935: sexta vértebra cervical procélica, MPEF 911: fragmento de punta xifiplastral, MPEF 874-875: placas periféricas del puente.

\section{Observaciones}

Esta especie aún indeterminada esta representada por una sexta vértebra cervical procélica (MPEF 935). El centro vertebral es corto y alto como la vértebra cervical del espécimen MPEF 932. Sin embargo, la vértebra del
MPEF 935 se diferencia de la vértebra de la especie 2 por la forma (de corazón) y las proporciones (tan ancho como alto) del cóndilo articular anterior, y por la forma del posterior (subrectangular). Otros rasgos destacados de la vértebra cervical de esta especie son: una cresta ventral rectilínea continua entre ambos cóndilos articulares, un par de procesos transversos que están localizados topográficamente entre la base del arco neural y la parte media del centro vertebral, así como el ángulo de $40^{\circ}$ formado entre la base del pedúnculo que soporta las postzigapófisis y el eje mayor del centro vertebral. Algunos de los rasgos arriba mencionados están presentes en los ejemplares de mayores dimensiones de Emydura macquarrii Gray. Por las diferencias entre los cóndilos articulares y el mayor tamaño (casi el doble en comparación con el MPEF 932) esta vértebra pertenece a un taxón diferente del descripto precedentemente (especie 2), pero con rasgos primitivos similares a los presentes en la vértebra cervical del ejemplar MPEF 932. Probablemente este tipo de vértebra cervical pueda corresponderse con caparazones no decorados de moderado tamaño.

\section{Chelidae Gen. et sp. indet. 4 Fig. 3, J-L}

\section{Material}

MPEF 878: placa periférica de puente, MPEF 834: placa periférica posterior; MPEF 910: fragmento del xifiplastron derecho.

\section{Observaciones}

Esta especie aún indeterminada está representada por un fragmento del xifiplastron derecho (MPEF 910) y por placas periféricas (MPEF 834, 878) decoradas con polígonos irregulares que por sus proporciones se corresponden con caparazones de dimensiones moderadas (longitud del caparazón dorsal 35-45 cm). Estas placas son indiferenciables, por su morfología y ornamentación, de las placas periféricas presentes en el ejemplar de Cerro Blanco, recuperado por la Dra Teresa Manera de Blanco (Museo de Punta Alta), de sedimentitas del Cretácico Superior en la provincia de Río Negro, con una longitud lineal del caparazón de $42 \mathrm{~cm}$. El caparazón ornamentado de Cerro Blanco presenta una conjunción de rasgos plesiomórficos (una placa nucal corta y ancha, ancho escudo cervical, mesoplastrones cortos y anchos) y apomórficos (el extremo medial del primer par de costillas torácicas elongado y estrecho), asociado con vértebras cervicales considerablemente más elongadas que las vértebras dorsales. Estos y otros rasgos derivados indican la pertenencia de este espécimen al grupo sudamericano Hydromedusa (de la Fuente et al., en prep.).

Chelidae Gen. et sp. indet. 5 Fig. 3, M-O; Fig. 4, A-B

\section{Material}

MPEF 819: placa pigal, MPEF 862: xifiplastron izquierdo, MPEF 865: fragmento de hioplastron izquierdo, MPEF 895 y MPEF 897: placas pleurales. 


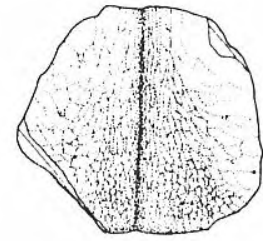

$A_{1}$

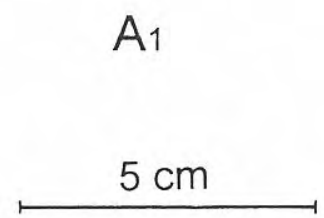

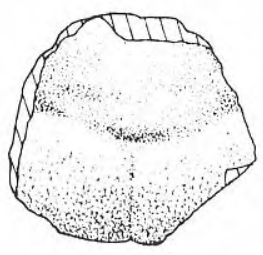

$\mathrm{A}_{2}$

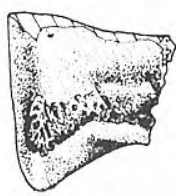

$\mathrm{B}_{1}$

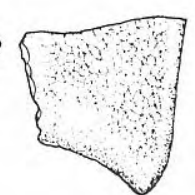

$\mathrm{B} 2$
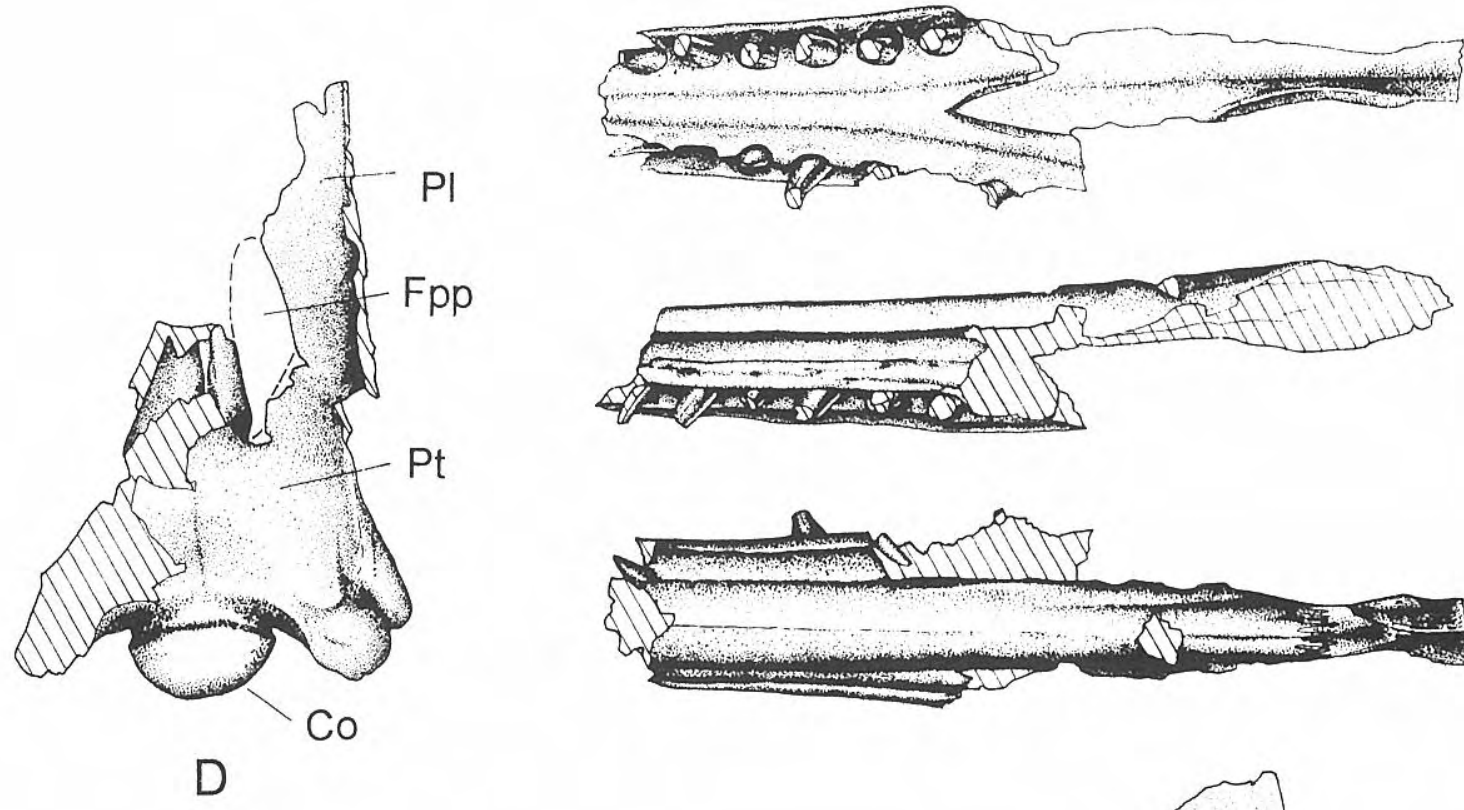

E1

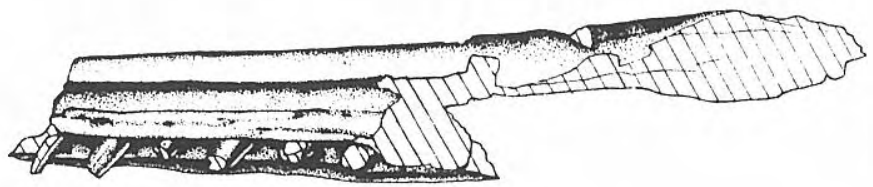

E2
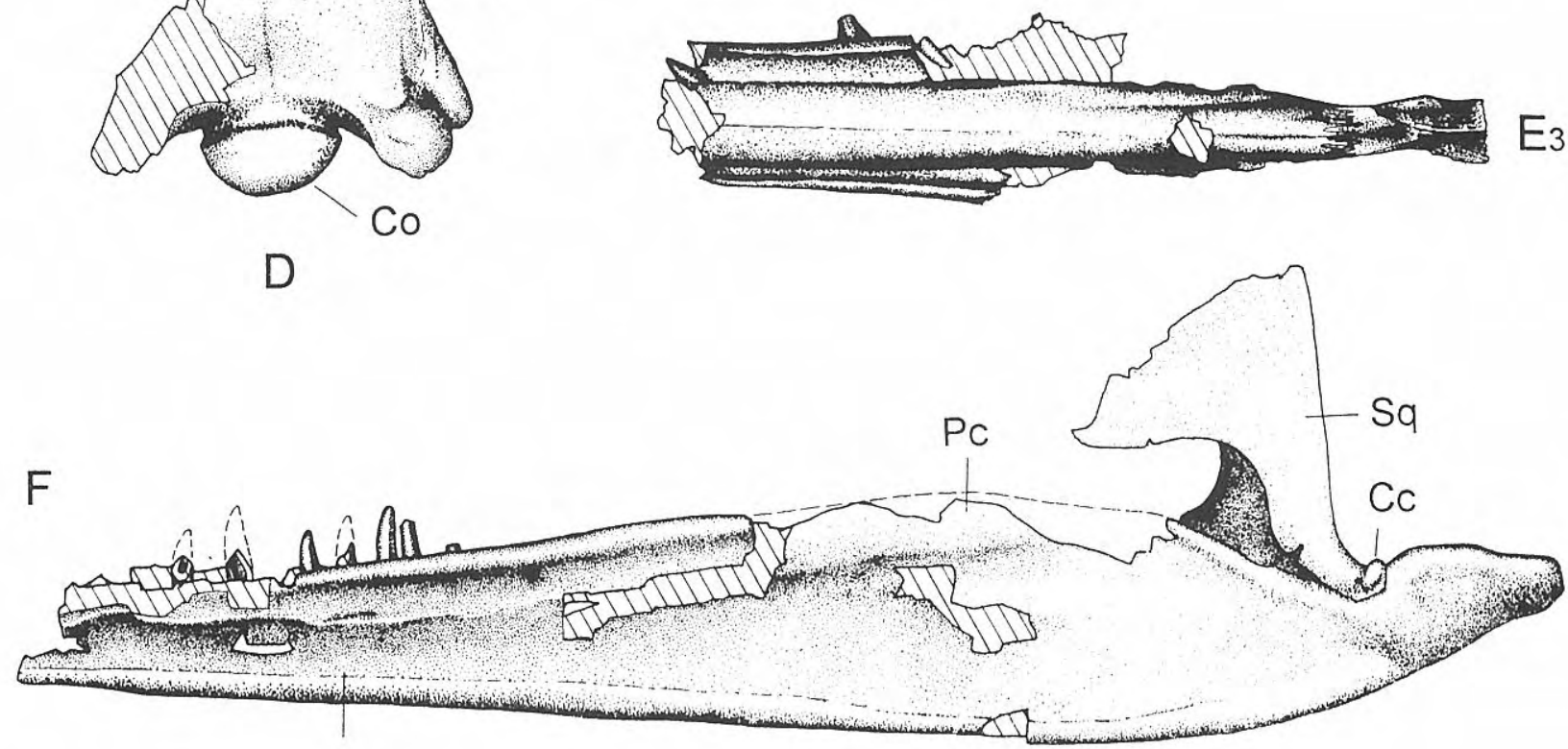

$\mathrm{D}$

Figura 4. Cerro Bosta. Formación La Colonia (Cretácico Superior).

Chelidae Gen. et sp. indet. 5 (A-B). A. MPEF 819. Placa pigal: A1- vista dorsal, A2- vista visceral. B. MPEF 862. Fragmento de un xifiplastron izquierdo: B1- vista visceral, B2-vista ventral.

Meiolaniidae Gen. et sp. indet. C. MPEF 859. Cuerno constituido por el escamoso derecho: C1-vista ventro-lateral, C2- vista dorso-lateral.

Polycotylidae. Sulcusuchus erraini Gasparini y Spalletti, 1990 (D-F) MPEF 650. D. Cóndilo occipital y basicráneo incompleto, vista ventral. E. Fragmento rostral con parte del puente fronto-parietal: E1- vista ventral, E2- vista lateral, E3- vista dorsal. F. Parte posterior del cráneo soldado a la mandíbula, vista lateral.

Abreviaturas. Co: cóndilo occipital, Cc: cóndilos articulares del cuadrado, D: dentario, Fpp: fenestra interpterigoidea posterior, Pc; proceso coronoideo, Pl: palatino, Pt: pterigoides, Sq: escamoso. 


\section{Observaciones}

Estos materiales podrían corresponder a una especie de pequeñas a medianas dimensiones (longitud del caparazón dorsal de 15 a $30 \mathrm{~cm}$ ), con un caparazón decorado con polígonos irregulares bien marcados, que en ciertas áreas del plastrón deviene en una ornamentación granulosa más densa. Esta especie es equivalente a la que ilustrara Broin (1987: Lám. I, figs. 15-22) como uno de los componentes de la queloniofauna de la Fm. Los Alamitos (Campaniense superiorMaastrichtiense), provincia de Río Negro. Los especímenes de mayores dimensiones son similares a los que Staesche (1929) nominó como "Najadochelys patagonica" para el Paleoceno de Punta Peligro (provincia de Chubut, Argentina).

\section{INFRAORDEN CRYPTODIRA Cope, 1868}

Familia Meiolaniidae Gunter, 1888

Los meiolánidos constituyen un peculiar grupo de tortugas extinguidas, con cornamenta craneana (formada por la extensión de los escamosos y el supraocccipital) y están restringidos en su distribución a América del Sur y Australasia. Los registros más antiguos proceden del Cretácico Superior de Patagonia (ver Broin, 1987; Broin y de la Fuente, 1993 b) y se extienden hasta el Eoceno en Patagonia (Simpson, 1938) y el Mioceno-Holoceno en Autralasia (ver Gaffney, 1981, 1983, 1996; Gaffney et al., 1984). En lo que respecta a sus relaciones filogenéticas, Gaffney $(1983,1996)$ ha considerado a los meiolánidos como primitivos eucriptodiros (ver discusión in Lapparent de Broin et al., 1996).

Meiolaniidae Gen. et sp. indet.

Fig. 4, C

\section{Material}

MPEF 859: Escamoso derecho.

\section{Observaciones}

Uno de los caracteres sinapomórficos de los meiolánidos (presentes en el ejemplar MPEF 859) es la extensión en dirección posterolateral del escamoso conformando una protrusión ósea. Dicho proceso en vida soportaría un cuerno. Según la nomenclatura propuesta por Simpson (1938), con las modificaciones sugeridas por Gaffney (1983) para las áreas de escudos del cráneo, la protrusión ósea del escamoso estaría cubierta por el escudo B.

Las diferentes proporciones (considerablemente menores) y morfología (superficie dorsal convexa y contorno más acuminado) de la protusión ósea del especímen MPEF 859 lo diferencian del proceso escamosal de Niolamia argentina Ameghino y sugieren la presencia de una diferente especie de meiolánido en la Formación La Colonia.

\section{SUBCLASE SAUROPTERYGIA Owen, 1860 ORDEN PLESIOSAURIA Blainville, 1835}

Durante el Cretácico los plesiosaurios fueron exitosos reptiles marinos que surcaron los mares de todo el mundo. Aunque sus restos se encuentran en todos los continentes incluyendo Antártida (Gasparini et al., 1984), es de América del Norte, de la "Western Interior Cretaceous Basin", de donde proviene la mayor cantidad y diversidad de plesiosaurios cretácicos (Bakker, 1993). En América del Sur, los registros abarcan desde el Aptiense en Colombia (Welles, 1962; Hampe, 1992) y Turoniense en Venezuela (Colbert, 1949; Welles, 1962) hasta el CampanienseMaastrichtiense en Brasil, Chile y Argentina (Gasparini y Goñi, 1985). Sin embargo, el conocimiento actual sobre los plesiosaurios cretácicos suramericanos es muy limitado y responde, en parte, a que predominan los fragmentos poscraneales aislados. Especímenes con cráneo, aun incompletos, son excepcionales y están restringidos a los plesiosauroideos (Welles, 1962; y material no descripto) y pliosauroideos (Hampe, 1992) del Aptiense de Colombia, el holotipo de Aristonectes parvidens Cabrera, 1941 del Maastrichtiense de Patagonia y el nuevo espécimen que aquí se refiere a Sulcusuchus erraini.

Gasparini y Spalletti (1990) describieron un nuevo Crocodyliforme sobre la base de un fragmento mandibular, hallado en los depósitos mareales del sector basal de la Fm. Coli Toro (Maastrichtiense), que aflora $25 \mathrm{~km}$ al norte de la localidad de Ing. Jacobacci, provincia de Rio Negro (Patagonia), Argentina. En ese trabajo lo refirieron a un nuevo género y nueva especie, Sulcusuchus erraini, asignándolo, con dudas, a los Dyrosauridae. En 1997, durante un trabajo de campo efectuado por personal del Museo Paleontológico E. Feruglio y del Museo de La Plata, se descubrió parte del cráneo y mandíbulas de un reptil longirrostro. De su comparación con el holotipo de Sulcusuchus erraini surge que corresponden al mismo taxón, pero éste debe ser referido a los Plesiosauria.

La sistemática de los plesiosaurios cretácicos está sustentada principalmente sobre la base de las formas de América del Norte (Williston, 1903, 1906; Welles 1943, 1962; Bakker, 1993; Carpenter, 1996, 1997). Varias formas longirrostras fueron referidas a los Polycotylidae, familia vinculada tradicionalmente con los Pliosauroidea (Persson, 1963; Brown, 1981). Sin embargo, en recientes estudios (Carpenter, 1996, 1997) son considerados como el grupo hermano de los Elasmosauridae (Plesiosauroidea), criterio que se sigue en este trabajo.

\author{
Superfamilia PLESIOSAUROIDEA Welles, 1943 \\ Familia Polycotylidae Cope, 1869 \\ Sulcusuchus Gasparini y Spalletti, 1990
}

Especie tipo: Sulcusuchus erraini Gasparini y Spalletti, 1990.

\section{Diagnosis enmendada}

Plesiosaurio de rostro largo, alto y muy angosto. Los 
espacios interalveolares son muy cortos y la mayoria de los dientes de recambio se encuentran junto al diente funcional, en el mismo alvéolo. Carece de foramen pineal, una sinapomorfía que comparte con elasmosáuridos y policotílidos del Cretácico tardío. El borde posterior externo del escamoso es vertical, carácter que comparte con Dolichorhynchops Williston, y lateralmente presenta una profunda escotadura. Como en Dolichorhynchops, los pterigoides forman una placa por debajo de la caja craneana, pero en Sulcusuchus es más extensa en sentido antero-posterior. Este carácter y un profundo surco en la cara lateral externa del maxilar y el dental son autapomorfías de Sulcusuchus.

\section{Sulcusuchus erraini Gasparini y Spalletti, 1990} Fig. 4, D-F

1996 Sulchusuchus erraini Gasparini, 166, 172, 181.

Holotipo: Museo de La Plata, MLP 88-IV-10-1. Fragmento de rostro (originalmente descripto como fragmento mandibular), Gasparini y Spalletti (1990, Lám. I).

Localidad tipo: margen noroeste de la laguna CariLaufquen Grande, $25 \mathrm{~km}$ al norte de Ing. Jacobacci, provincia de Río Negro, Argentina. Sector Basal de la Fm. Coli-Toro, Maastrichtiense (Gasparini y Spalletti, 1990).

Material referido: MPEF 650. Cóndilo occipital y basicráneo incompleto (Fig. 3, D), un fragmento rostral con parte del puente frontal-parietal (Fig.3, E1-E3), parte posterior izquierda del cráneo soldado a la mandíbula (Fig. $3, \mathrm{~F})$, y dos fragmentos mandibulares.

Procedencia geográfica y estratigráfica: Cerro Bosta $\left(43^{\circ}\right.$ 00' 21" S; 67³7' 13" O) (Fig. 1), Miembro medio de la Fm. La Colonia, niveles con Reigitherium Bonaparte, Campaniense-Maastrichtiense (R. Pascual, com. pers.).

Diagnosis enmendada: la misma del género por monotipia.

\section{Descripción}

El fragmento rostral y la mandíbula (Fig. 4, E1-E3 y F) indican que perteneció a una forma de rostro largo, muy angosto y alto. Este es un morfotipo poco frecuente entre los plesiosaurios y comparable al de Dolichorhynchus osborni Williston, del Cretácico tardío de América del Norte (Carpenter, 1997). En el dorso del rostro (Fig. 3, E3) participan los premaxilares que conforman un único domo, que se angosta y divide en dos domos más estrechos al hacer contacto con el frontal. El frontal está muy incompleto, uniéndose al parietal con una sutura irregular. No hay indicios de foramen pineal. La falta de foramen pineal es un carácter que Carpenter (1997) destaca como sinapomorfia compartida por los elasmosáuridos y policotílidos del Cretácico tardío. Uno de los caracteres más conspicuos en el rostro y la mandíbula de Sulcusuchus es el profundo surco sobre la cara externa del maxilar y el dental, paralelo a la línea dentaria (Fig. 3, E2, E3, D). Surcos no tan profundos, pero de posición similar, están presentes en Macroplata longirostris (Blake), un Pliosauridae del Lías superior de Inglaterra (White, 1940), y en la mayoría de los ictiosaurios.

En vista ventral, el vómer es una angosta barra medial entre los maxilares, que se ensancha hacia atrás (Fig. 3, E1), de manera similar a lo que sucede en Dolichorhynchops osborni (Carpenter, 1997, Fig. 3B, Fig. 6C). Lamentablemente, no son visibles las suturas que delimitan el vómer de los pterigoides y falta un sector importante del paladar. Se conservó parte del palatino izquierdo que, junto con una incompleta proyección sagital del pterigoides, delimita parte de la fenestra interpterigoidea anterior. Los pterigoides, por detrás de las fenestras interpterigoideas posteriores, son muy amplios y forman una placa, casi plana y mucho mas extensa, hacia atrás, que la de Dolichorhynchops (Carpenter, 1997, Fig.9 D) y la de Trinacromerum bentonianum Cragin, un policotílido del Turoniense de Kansas (Carpenter, 1996, Fig. 14 B).

En vista occipital, el cóndilo formado por el basioccipital es subesférico y está constreñido por un fuerte surco (Fig. 3, D). El cuadrado izquierdo es alto y angosto y está fusionado al escamoso. Los cóndilos articulares del cuadrado están soldados en la fosa glenoidea. En vista lateral (Fig. 3, F), el escamoso tiene el borde posterior externo fuertemente vertical, como en Dolichorhynchops (Carpenter, 1996, Fig. 7), y una profunda escotadura lateral. Esta escotadura en el escamoso es equivalente a la que presentan algunos pliosáuridos jurásicos, tales como Pliosaurus brachyspondilus (Owen) (ver Taylor y Cruickshank, 1993), y cretácicos (Brachauchenius lucasi Williston), y en criptoclídidos, como Kimmerosurus Brown y Cryptoclidus eurymerus (Plillips) (Brown, 1993). Por el contrario, en Trinacromerum bentoniamum, la escotadura es baja (Carpenter, 1996, Fig. 14, 16) y en Dolichorhynchops osborni, es muy baja (Carpenter, 1997, Fig. 3C; 6A).

De la mandíbula del MPEF 650 se preservaron dos sectores. Uno anterior, que corresponde a la parte posterior de la sínfisis e incluye 7 pares de alvéolos, y otro posterior izquierdo, que se extiende desde el proceso retroarticular al alvéolo 19, contando desde atrás. Todo este sector mandibular es muy comprimido, con una marcada depresión en la cara externa del dental, que es la continuación del surco que caracteriza a Sulcusuchus. A la altura del proceso coronoideo, la rama mandibular es más alta que en Dolichorhynchops, bajando de manera también más abrupta hasta el borde anterior de la fosa glenoidea (Fig. 3, F), carácter que comparte con Trinacromerum bentonianum (Carpenter, 1996, Fig. 16). Excepto el esplenial, en la cara interna, y el angular que se proyecta como una cuña ventral, no se observan otros contactos o suturas. El proceso retroarticular es comprimido y con la base elevada hacia atrás y sagitalmente, mientras que su cara dorsal es deprimida. En Dolichorhynchops, la base del proceso retroarticular es plana (Carpenter, 1997, Fig. 6 A-B) y en Trinacromerum bentonianum (KUVP 5070) (Carpenter, 1996, Fig. 16), es similar a la de Sulcusuchus erraini.

Un carácter de Sulcusuchus, ligado a la longirrostría y que comparte con Dolychorhynchops, es la falta de alvéolos para los dientes de reemplazo, excepto en los sectores más anchos del paladar, como por ejemplo los últimos de un 
fragmento maxilar izquierdo. Los alvéolos para los dientes funcionales son subcirculares y subiguales. Los dientes son cónicos, acuminados, ligeramente curvados y estriados. En alguno de ellos se observa desgaste en la cara anterior, y en un fragmento mandibular del MPEF 650 hay alternancia de dientes gastados con otros de reciente reemplazo, además de la erupción, en el mismo alvéolo, de un nuevo diente. El holotipo de Sulcusuchus erraini, un fragmento maxilar (descripto erróneamente como mandibular), tiene las mismas características: un profundo surco y una sola hilera de alvéolos. Para la descripción del holotipo se efectuaron cortes transversales (Gasparini y Spalletti, 1990, Lám. I) y el único diente conservado estaba perfectamente encastrado en el alvéolo, con la raíz fuertemente orientada hacia atrás, como ocurre en los cocodrilos longirrostros. La falta de alvéolos suplementarios para los dientes de reemplazo y la forma de encastre de ese diente fueron los caracteres que sirvieron fundamentalmente para referirlo a los Crocodyliformes y, con dudas, a los Dyrosauridae.

\section{Discusión}

Los recientes trabajos de Bakker (1993) y principalmente de Carpenter (1996, 1997) sobre plesiosaurios cretácicos de América del Norte han aportado nuevos enfoques para la interpretación filogenética de estos reptiles marinos. Aunque aún no se han presentado análisis cladísticos en sentido estricto se han valorado caracteres, principalmente craneales, que sirvieron de base para nuevas propuestas taxonómicas. De este modo, Carpenter (1996) concluye que los Polycotylidae, familia de plesiosaurios cretácicos de cuello corto, son el grupo hermano de los Elasmosauridae (de cuello largo) y no están estrechamente vinculados a los Pliosauridae como tradicionalmente se aceptó. Caracteres tales como la fenestra vómero-nasal, la expansión de los pterigoides en una placa bajo la caja cefálica, y la pérdida del foramen pineal y la columela justificarían las estrechas relaciones. Sulcusuchus comparte la expansión de los pterigoides y la falta de foramen pineal (los otros dos caracteres faltan por deterioro del material). Asimismo, Sulcusuchus es considerado un Polycotylidae (Carpenter, 1996, 1997) por el rostro y sínfisis mandibular largos y angostos, los dientes cónicos, de tamaño uniforme ( $\sin$ caniniformes como en Pliosauridae), y los pterigoides planos formando una amplia placa.

Comparándolo con los Polycotylidae recientemente revisados (Carpenter, 1996, 1997), Sulcusuchus comparte con Dolychorhynchus una más acentuada longirrostría, la falta de alvéolos expuestos para los dientes de reemplazo, los dientes largos, delgados y finamente estriados, y el borde latero-posterior del escamoso vertical. Se diferencian porque el cráneo de Sulcusuchus es más comprimido, y la longirrostría probablemente más acentuada. Aunque no se conoce el número de dientes en el maxilar o la mandíbula, los espacios interalveolares son más cortos que en Dolychorhynchops. Además, Sulcusuchus posee una escotadura lateral en el escamoso muy excavada, y la placa que conforman los pterigoides está mas desarrollada, particularmente en sentido antero- posterior. Estos dos caracteres, más el fuerte surco lateral en el maxilar y el dental, son las autapomorfías que soportan la validez del taxón.

\section{LOS REPTILES DE LA FORMACIÓN LA COLONIA}

Excepto los plesiosaurios, todos los vertebrados registrados en el sector medio de la Fm. La Colonia son formas terrestres o de agua dulce (peces, tortugas, ofidios, dinosaurios, aves y mamíferos). Los niveles portadores han sido interpretados como depositados en un estuario, llanura de mareas o un ambiente de planicie costera (Pascual, com. pers.), por lo que la mezcla de vertebrados procedentes de distintos ambientes está justificada, más aún cuando predominan los fragmentos aislados (dientes, placas, escamas, vértebras ).

Con respecto a los plesiosaurios, además del cráneo de Sulsuchus erraini y de un poscráneo articulado aún en preparación, se exhumaron gran cantidad de vértebras aisladas que indican la presencia de otros taxones, entre ellos los elasmosáuridos. En reiteradas ocasiones se mencionó el registro de plesiosaurios jurásicos y cretácicos en sedimentitas "no marinas" (Cruickshank, 1997). Sin embargo, a estos reptiles se los encontró asociados con foraminíferos costeros y siempre se destacó el carácter de lagoon o deltaico-costero de los ambientes. Nada impide suponer que algunos plesiosaurios remontaran ocasionalmente tramos de ríos próximos a su desembocadura, como ocurre en los grandes estuarios actuales con los cetáceos y las tortugas marinas, pero no significa que estos representen sus hábitats naturales. Hacia fines del Cretácico, y como consecuencia de transgresiones del Atlántico Sur sobre gran parte de Patagonia, la región se transformó en un gran archipiélago (Bond et al., 1995), un ambiente óptimo para sustentar la diversidad de plesiosaurios. A los policotílidos y elasmosáuridos de La Colonia, se suman, más al noroeste de Patagonia (Lago Pellegrini, Rio Negro) elasmosáuridos de cuello largo (Gasparini y Salgado, 2000, en este número); mientras que en el centro-norte (Chubut) se halló el peculiar Aristonectes parvidens Cabrera. Es interesante destacar que Casamiquela (1978) ya había mencionado varias localidades del norte de la Patagonia donde afloran distintas unidades litoestratigráficas referidas al Cretácico tardío, correspondientes a los ambientes litorales de la gran transgresión atlántica que él denominó "Mar de Káwas”. La Colonia está en el área de influencia de esa gran ingresión (Bertels, 1970, fig. 5; Casamiquela, op. cit., Fig.1). Asimismo, Casamiquela (1978) advirtió similitudes entre la fauna de Patagonia y las del centro de América del Norte y, sobre la base de los vertebrados del "Mar de Káwas", dedujo que había habido algún tipo de conexión en la biota, a lo largo de las costas del "paleoAtlántico". La presencia del policotílido Sulcusuchus apoya su hipótesis. Con los nuevos hallazgos y fundamentalmente con los nuevos estudios, las determinaciones preliminares de Casamiquela fueron 
modificándose (Casamiquela, 1978, pág. 140, refirió como Ichthyosauria indet. el fragmento maxilar que Gasparini y Spalletti, 1990, designaron como holotipo de Sulcusuchus y que aquí se refiere a los policotílidos), pero varias de sus hipótesis sobre paleoambientes y distribución geográfica de esas faunas hoy están reforzadas por evidencias taxonómicas más sólidas.

Entre las tortugas de la Fm. La Colonia, un solo resto confirma la presencia de meiolánidos, formas indudablemente terrestres y fuertemente acorazadas. Las demás son quélidos, todas formas de agua dulce, pertenecientes a cinco taxones, con una diversidad genérica y en menor medida específica alta que es comparable a la existente en otros yacimientos del Cretácico tardío y del Paleoceno de Patagonia (e.g. El Abra y Los Alamitos, Salinas de Trapalcó, Punta Peligro). En estas localidades pueden ser reconocidas especies extintas pertenecientes a los grupos vivientes de Australasia (Emydura) y América del Sur (Phrynops, Chelus e Hydromedusa) (ver Broin y de la Fuente, 1993 b). Teniendo en cuenta el paleoambiente de estuario que representa el nivel portador de los fósiles, es entendible encontrar tal riqueza especifica de tortugas. Las mismas pudieron ser transportadas en períodos de inundaciones a través de las planicies de inundación de los ríos hacia su desembocadura. La marcada diversidad de tamaños (de grande, moderado a pequeño) que se encuentran en las tortugas recuperadas de la Formación La Colonia en Cerro Bosta sugieren la existencia de distintos hábitos y nichos ecológicos. En tal sentido, las formas carnívoraspiscívoras podrían estar adaptadas a depredar sobre presas de distinto tamaño. Incluso las formas piscívoras podrían haber desarrollado distintas técnicas de captura, como las descritas para los quélidos actuales (Pritchard, 1984 b). Otras podrían haber tenido hábitos omnívoros. Entre ellas pudieron cubrir un amplio rango de nichos ecológicos: haber habitado corrientes calmas o rápidas de los ríos, merodear en los fondos o habitar distintas profundidades en los cursos de agua. Alguna de estas especies pudo desplazarse por el substrato en los márgenes de los ríos, desarrollando hábitos semiacuáticos. Tampoco puede descartarse la adaptación de alguna de ellas a la vida en el estuario, como sucede en la actualidad con el quélido Hydromedusa tectifera (ver Frazier, 1986). Por otra parte, en la actualidad un gran número de especies simpátridas ocupan un área determinada. Por ejemplo, en la Cuenca Amazónica (río Amazonas y el confluente Río Branco), en los alrededores de Manaos (Lapparent de Broin, com. pers.) se ha contabilizado la presencia de hasta catorce especies de tortugas ( 5 de quélidos, 5 de podocnemídidos, 2 de testudínidos, 1 de kinostérnidos y 1 de bataguridos) (cf. Iverson, 1986).

Desde un punto de vista paleobiogeográfico, la herpetofauna de La Colonia está integrada por clados de distinto origen. Las tortugas son indudablemente surgondwánicas. Tanto los quélidos como los meiolánidos se distribuyen en Patagonia (Cretácico inferior-Paleógeno) y Australasia (Eoceno-Holoceno) (ver Broin y de la Fuente, 1993 a, b; Lapparent de Broin, com.pers.). Coincidentemente, entre los ofidios de La Colonia se ha determinado la presencia del Madtsoiidae Alamitophis Albino, 1986, un género presente en el Cretácico tardío de Patagonia (Albino, 1986) y en el Eoceno de Australia (Scanlon, 1993), además de probablemente los más antiguos boideos registrados en América del Sur (Albino, en prensa). En tal sentido, las tortugas como los ofidios indican estrechas vinculaciones biogeográficas entre Patagonia y Australasia, vía Antártida. Por su parte, la presencia de dientes que pueden ser referidos a cf. Carnotaurus confirma el registro de Abelisauridae en la Formación La Colonia. Esta familia de terópodos ceratosaurios presenta una particular distribución en Patagonia (Abelisaurus Bonaparte y Novas, Carnotaurus Bonaparte), la India (Indosurus Huene y Matley, Indosuchus Huene y Matley) y Madagascar (Majungatholus Sues y Taquet). Una de las hipótesis enunciadas por Sampson et al. (1998) para explicar esta peculiar distribución geográfica plantea que este grupo de dinosaurios se originó en el Cretácico Inferior después del aislamiento de Africa, dispersándose entre América del Sur y la región Indo-Malgache vía Antártida. Esta hipótesis postula también la utilización de un puente terrestre, el "Kerguelen Plateau", para dicha dispersión. Finalmente, los plesiosaurios policotílidos han sido hallados principalmente en el Western Interior Sea de América del Norte, donde se registra la mayor diversidad de este grupo y donde uno de los taxones, Dolichorhynchops, está cercanamente relacionado con Sulcusuchus. Desde un análisis tectonosedimentario, la separación de Africa del noreste de Brasil se produjo durante el Aptiense-Albiense (Guiraud y Maurin, 1991), favoreciendo una franca conexión entre el Atlántico Sur y el ecuatorial, por lo que potencialmente fue la vía de dispersión para muchos grupos de organismos marinos, entre ellos, los plesiosaurios. La presencia de plesiosaurios extremadamente longirrostros en la Patagonia tiene interés para futuras interpretaciones sobre las cadenas tróficas. Los ictiosaurios ya se habían extinguido, y el nicho que ocupaban los longirrostros marinos estaba representado, como en el Western Interior Sea (Bakker, 1993), por los cocodrilos dyrosáuridos (Brasil-Africa) y por los policotílidos más derivados.

\section{AGRADECIMIENTOS}

Los autores agradecen a los Dres. Rosendo Pascual y Rubén Cúneo la invitación a estudiar parte de los reptiles provenientes de La Colonia. Asimismo, destacan la labor de campo de Pablo Puerta (Museo E. Feruglio) y Dr. Marcelo Reguero (Museo de La Plata), y la de preparación de los ejemplares estudiados (P. Puerta, y Arq. Javier Posik, Museo de La Plata). A la Dra. France de Lapparent de Broin (Muséum national d'Histoire naturelle de Paris), la información suministrada sobre tortugas fósiles y actuales. Los dibujos fueron efectuados por Jorge González. La edición fue realizada por Laura Zampatti. Este estudio estuvo financiado por el Programa de Incentivos de la Universidad Nacional de La Plata (N 186 y N 298), PEI 0081/97 
(CONICET), y CONICET-PIP 0062/98. Los autores son investigadores del Consejo Nacional de Investigaciones Científicas y Técnicas (CONICET), Argentina.

\section{BIBLIOGRAFÍA}

Albino, A. 1986. Nuevos Boidae Madtsoiinae en el Cretácico tardío de Patagonia (Formación Los Alamitos, Río Negro, Argentina). IV Congreso Argentino de Paleontología y Bioestratigrafía, 2, 15-21.

Albino, A. (en prensa). New record of snakes from the Cretaceous of Patagonia (Argentina). Geodiversitas.

Bakker, R.T. 1993. Plesiosaur extinction cycles-events that mark the beginning, middle and end of the Cretaceous. In: Evolution of the Western Interior Basin (Eds. W. Caldwell and C. Kauffman). Geological Association of Canada, Special Paper, 39, 641-644.

Bertels, A. 1970. Los foraminíferos planctónicos de la Cuenca Cretácico-Terciaria en Patagonia Septentrional (Argentina), con consideraciones sobre la Estratigrafía de Fortín Gral Roca (Prov. de Río Negro). Ameghiniana, 7, $1-56$.

Bona, P., Cladera, G. y Fuente, M. de la. 1998. Las tortugas pleurodiras de la Formación Salamanca (Paleoceno inferior) en el área de Cerro Hansen, Provincia de Chubut, Argentina. X Congreso Latinoamericano de Geología y VI Congreso Nacional de Geología Económica, 1, 269-274.

Bonaparte, J. F., Franchi, M., Powell, J. y Sepúlveda, E. 1984. La Formación Los Alamitos (CampanianoMaastrichrtiano) del sudeste de Río Negro, con descripción de Kritosaurus australis n. sp. (Hadrosauridae). Significado paleogeográfico de los vertebrados. Revista de la Asociación Geológica Argentina, 39 (3-4), 284-299.

Bond, M., Carlini, A.A., Goin, F. J., Legarreta, L., OrtizJaureguizar, E., Pascual, R. and Uliana, M. A. 1995. Episodes in South American Land Mammal evolution and Sedimentation testing their apparent concurrence in a Paleocene succession from Central Patagonia. VI Congreso Argentino de Paleontología y Bioestratigrafía, Trelew, Actas, 45-58.

Broin, F. de. 1987. The Late Cretaceous Fauna of Los Alamitos, Patagonia, Argentina Part IV Chelonia. Revista Museo Argentino de Ciencias Naturales "Bernardino Rivadavia" Paleontología, 3 (3), 131-139.

Broin, F. de et Fuente, M. de la. 1993a. Les tortues fossiles d'Argentine: première synthèse. Table Ronde Européenne Paléontologie et Stratigraphie d'Amerique latine. Lyon, 1992. Documents des laboratoires de Géologie Lyon, 125, 73-84.

Broin, F. de et Fuente, M. de la. 1993b. Les tortues fossiles d'Argentine: Synthèse. Annales de Paléontologie, 79 (3), 169-232.

Brown, D. 1981. The English Upper Jurassic Plesiosauroidea (Reptilia) and a review of the phylogeny and classification of the Plesiosauria. Bulletin of the British Museum of Natural History (Geology), 35, 253347.
Brown, D. 1993. A taxonomic reappraisal of the families Elasmosauridae and Cryptoclididae (Reptilia: Plesiosauroidea). Revue de Paléobiologie, vol Spéc., 7, 9-16.

Cabrera, A. 1941. Un plesiosaurio nuevo del Cretácico del Chubut. Revista del Museo de La Plata (N.S.) $2 S$. Palentología, 2 (8), 113-130.

Carpenter, K. 1996. A review of short-necked plesiosaurs from the Cretaceous of the Western Interior, North America. Neues Jahrbuch Geologie und Palaontologie, Abh., 201, 259-287.

Carpenter, K. 1997. Comparative cranial anatomy of two North American Cretaceous plesiosaurs. In: Ancient Marine Reptiles (Eds. J. Callaway and E. Nicholls). Academic Press, San Diego, 191-216.

Casamiquela, R. 1978. La zona litoral de la transgresion Maastrichtiense en el norte de la Patagonia. Aspectos ecológicos. Ameghiniana, 15, 137-148.

Colbert, E. H. 1949. A new Cretaceous plesiosausaur from Venezuela. American Museum Novitates, 1420, 1-22.

Cruickshank, A. 1997. A Lower Cretaceous pliosauroid from South Africa. Annals of the South African Museum, 105, 207-226.

Frazier, J. 1986. Epizoic Barnacles on Pleurodiran Turtles: is the relation rare? Proceedings Biological Society of Washington, 99, 472-477.

Gaffney, E. S. 1977. The Side-Necked Turtle Family Chelidae: A Theory of Relationships Using Shared Derived Characters. American Museum Novitates, 2620, 1-28.

Gaffney, E. S. 1981. A review of the fossil turtles of Australia. American Museum Novitates, 2737, 1-38.

Gaffney, E. S. 1983. The cranial morphology of the extinct horned turtle Meiolania platyceps, from the Pleistocene of Lord Howe Island, Australia. Bulletin American Museum of Natural History, 175, 326-479.

Gaffney, E. S. 1996. Postcranial morphology of Meiolania platyceps and a review of the Meiolaniidae. Bulletin of the American Museum of Natural History, 229, 1-166.

Gaffney, E. S. and Meylan, P. 1988. A phylogeny of turtles. In: The Phylogeny and Classification of the Tetrapods. I Amphibians, Reptiles, Birds (Ed. M. J. Benton). Systematic Association Spec, 35 A, 5, 157-219. Clarendon Press, Oxford.

Gaffney, E. S., Balouet, C. and Broin, F. de. 1984. New ocurrences of extinct meiolanid turtles in New Caledonia. American Museum Novitates, 2800, 1-6.

Gasparini, Z. 1996. Biogeographic Evolution of the South American Crocodilians. In: Contributions of southern South America to Vertebrate Paleontology (Ed. G. Arratia). Müchner Geowissenschaftliche Abhandlungen (A), 30, 159-184.

Gasparini, Z. y Goñi, R. 1985. Los plesiosaurios Cretácicos de América del Sur y del Continente Antártico. Actas VII Congresso Brasileiro de Paleontología, 1983. Coletanea de Trabalhos Paleontológicos, Série Geología, 27 (2), 55-63.

Gasparini, Z. y Salgado, L., 2000. Elasmosauridos (Plesiosauria) del Cretácico tardío del Norte de Patagonia. Revista Española de Paleontología, 15, 13-21. 
Gasparini, Z. y Spalletti, L. 1990. Un nuevo cocodrilo en los depósitos mareales maastrichtianos de la Patagonia noroccidental. Ameghiniana, 27, 141-150.

Gasparini, Z., Del Valle, R. y Goñi, R. 1984. Un elasmosaurido (Reptilia, Plesiosauria) del Cretácico Superior de la Antártida. Instituto Antártico Argentino. Contribución 305, 1-24.

Giraud, R. et Maurin, J. C. 1991. Le rifting en Afrique au Crétace inferieur: synthèse structurales, mise en evidence de deux etapes dans la genese des bassins, relations avec les ouvertures oceaniques pre-africaines. Bulletin Société géologique de France, 162, 811-823.

Hampe, O. 1992. Ein grosswuchsiger Pliosauride (Reptilia: Plesiosauria) aus der Unterkreide (oberres Aptium) von Kolumbien. Courier Forschungsinstitut Senckenberg, 145, 1-32.

Iverson, J. B. 1986. A checklist with Distribution Maps of the Turtles of the World. Edición del Autor. Richmond (Indiana), 1-283.

Lapparent de Broin F. de y Fuente, M. de la. 1999. Particularidades de la fauna Continental de tortugas de Cretácico de Argentina. XIV Jornadas Argentinas de Paleontología de Vertebrados (Neuquén, 1998). Ameghiniana, 36, 104.

Lapparent de Broin F. de, Lange-Badré, B. et Dutrieux, M. 1996. Nouvelles decouvertes de tortues dans le Jurassique Supérieur du Lot (France) et examen du taxon Plesiochelyidae. Revue de Paléobiologie, 15, 533570.

Lapparent de Broin, F de, Fuente, M. de la y Calvo, J. 1997. Presencia de los más antiguos quélidos (Tortugas pleurodiras) en el Cretácico Inferior de El Chocón, provincia del Neuquén, Argentina. XIII Jornadas Argentinas de Paleontología de Vertebrados (La Rioja). Ameghiniana, 34, 538.

Legarreta, L., Kokogian, D. and Boggettti, D. 1989. Depositional sequences of the Marlargue Group (Upper Cretaceous-Lower Tertiary), Neuquén Basin, Argentina. Cretaceous Research, 10, 337-356.

Pascual, R., Ortiz-Jaureguizar, E. and Prado, J. L. 1996. Land Mammals Paradigm for Cenozoic South American Geobiotic Evolution. In: Contributions of Southern South America to Vertebrate Paleontology (Ed. G. Arratia). Müchner Geowissenschaftliche Abhandlungen, (A), 30, 265-319.

Persson, P. 1963. A revision of the classification of the Plesiosauria, with a synopsis of the stratigraphical and geographical distribution of the group. Lunds Universitets Arsskrift, N.F. 2, 59, 1-60.

Pesce, A. 1979. Estratigrafía del Arroyo Perdido en su tramo medio e inferior, Provincia del Chubut. $7^{\circ}$ Congreso Geológico Argentino, Neuquén, Actas, 1, 315-333.
Pritchard, P. C. H. 1984a. Evolution and Zoogeography of south american turtles. Stvdia Geologica Salmanticensia. Stvdia Palaeocheloniologica, 1, 225-233.

Pritchard, P. C. H. 1984b. Piscivory in Turtles, and Evolution of the Long-necked Chelidae In: Structure, Development and Evolution of Reptiles (Ed. M. W. J. Ferguson). Symposium zoological Society of London, 52, $87-110$

Pritchard, P. C. H. and Trebbau, P. 1984. The Turtles of Venezuela. Contribution to Herpetology, 12, 1-403. Society Studies Amphibians, Reptiles publications. Miami.

Sampson S. D., Witmer, L. M., Forster, C. A., Krause, D. W., O'Connor, P. M., Dodson, P. and Ravoavy, F. 1998. Predatory Dinosaur Remains from Madagascar: Implications for The Cretaceous Biogeography of Gondwana. Science, 280, 1048-1051.

Scanlon, J. 1993. Madtsoiid snakes from the Eocene Tingamarra Fauna of Esatern Queensland. Kaupia, Darmastädter Beiträge zur Naturgeschichte, 3, 3-8.

Shaeffer, H. B., Meylan, P. and Mc Knight, M. L. 1997. Test of the turtle phylogeny: Molecular, morphological and paleontological approaches. Systematic Biology, 46, 235 268.

Simpson, G. G. 1938. Crossochelys Eocene horned turtle from Patagonia. Bulletin American Museum of Natural History, 74, 221-254.

Staesche, K. 1929. Schildkrötenreste aus der oberenKreide Patagoniens. Paleontographica, 72, (1-6), 103-112.

Taylor, M. and Cruickshank, A. 1993. Cranial anatomy and functional morphology of Pliosaurus brachyspondylus (Reptilia: Plesiosauria) from the Upper Jurassic of Westbury, Wiltshire. Philosophical Transactions of the Royal Society of London (series B), 341, 399-418.

Welles, S.P. 1943. Elasmosaurid plesiosaurs with description of new material from California and Colorado. Memoir University of California Publications in Geological Sciences, 13, 125-254.

Welles, S.P. 1962. A new species of elasmosaur from the Aptian of Colombia and a review of the Cretaceous Plesiosaurs. University of California Publications in Geological Sciences, 44 (1), 1-96.

White, T. 1940. Holotype of Plesiosaurus longirostris Blake and classification of the plesiosaurs. Journal of Paleontology, 14, 451-467.

Williston, S. 1903. The skull of Brachauchenius, with observations on the relationships of the plesiosaurs. Proceeding United States National Museum, 32 (1540), 477-489.

Williston, S. 1906. North American plesiosaurs: Elasmosaurus, Cimoliasaurus, and Polycotylus. American Journal of Science, 4 (21), 221-236. 